\title{
Motivação e trabalho: investigação sobre a experiência dos jovens no primeiro emprego
}

\section{Motivación y trabajo: investigación sobre la experiencia de los jóvenes en el primer empleo}

\section{Motivation and work: investigation on the experience of young people at first employment}

\author{
Amanda Dias Dourado \\ ORCID ID: 0000-0003-2709-6367 \\ Programa de Pós Graduação em Psicologia Social da Universidade Federal da \\ Paraíba (PPGPS/UFPB),Brasil \\ Paulo César Zambroni-de-Souza \\ ORCID ID: 0000-0002-7353-4420 \\ Programa de Pós Graduação em Psicologia Social da Universidade Federal da \\ Paraíba (PPGPS/UFPB), Brasil \\ Autor referente: amandadouradorh@gmail.com \\ Historia editorial \\ Recibido: 01/12/2018 \\ Aceptado: 15/06/2020
}

\section{RESUMO}

Os altos índices de desemprego e rotatividade nas empresas juntamente com as novas configurações do trabalho apresentam desafios para a inserção do jovem no âmbito profissional. Nesse cenário, a motivação pode auxiliá-lo a obter uma carreira promissora. Para tanto, o destaque do presente estudo foi investigar qual foi a motivação dos jovens para começar a trabalharem comparação com a motivação para permanecer no trabalho. Trata-se de um estudo qualitativo com uma amostra não probabilística por conveniência, que foi composta por 30 jovens com idades entre 18 e 23 anos, que se encontram no primeiro emprego na função de assistente administrativo como Jovem Aprendiz de um Centro de Integração Empresa-Escola localizado na Paraíba, Brasil.Para coleta de dados foram utilizados dois instrumentos: um questionário contendo dados sociodemográficos e um questionário norteado pelosobjetivos do estudo em questão, analisado pela técnica de análise de conteúdo temática e categorial. Foi possível perceber que para a maioria dos jovens sua motivação inicial para trabalhar está na remuneração, experiência e ajudar a família e sua motivação para continuar trabalhando consistiu em alcançar 
independência e sucesso profissional. Esses resultados se relacionam com a teoria motivacional da Hierarquia das Necessidades de Maslowe trazem implicações para a atenção das autoridades sobre a saudável inserção do jovem no mercado de trabalho, considerando que os primeiros passos profissionais produzem efeitos na carreira dessa geração e no futuro das empresas e do país.

Palavras-chave: Motivação; jovem aprendiz; trabalho

\section{RESUMEN}

Los altos índices de desempleo y rotación en las empresas junto con las nuevas configuraciones del trabajo presentan desafíos para la inserción del joven en el ámbito profesional. En este escenario, la motivación puede ayudar a alcanzar una carrera prometedora. Para ello el presente estudio se enfocó en investigar cuál fue la motivación de los jóvenes para empezar a trabajar en comparación con la motivación para permanecer en el trabajo. Se trata de un estudio cualitativo con una muestra no probabilística por conveniencia que estuvo integrada por 30 jóvenes con edades entre 18 y 23 años que se encuentran en el primer empleo como Joven Aprendiz en la función de asistente administrativo de un Centro de Integración Empresa-Escuela ubicado en Paraíba, Brasil. Para la recolección de datos, se utilizaron dos instrumentos: un cuestionario que contenía datos socio-demográficos y un cuestionario orientado por los objetivos del presente estudio, se condujeron análisis de contenido temático y categorial. Es posible percibir que para la mayoría de los jóvenes su motivación inicial para trabajar se conecta con la remuneración, experiencia y ayudar a la familia y su motivación para continuar trabajando se vincula a alcanzar independencia y éxito profesional. Estos resultados se relacionan con la teoría motivacional de la Jerarquía de las Necesidades de Maslow y tienen implicaciones para la atención de las autoridades sobre la inserción saludable del joven del joven en el mercado de trabajo, considerando que los primeros pasos profesionales producen efectos en la carrera de esa generación y en el futuro de las empresas y del país.

Palabras clave: Motivación; joven aprendiz; trabajo

\section{ABSTRACT}

The high rates of unemployment and turnover in companies together with the new job configurations present challenges for the insertion of the young person in the professional scope. In this scenario, motivation can help you get a promising career. Therefore, the focus of the present study was to investigate the motivation of the young people to start working compared to the motivation to remain at work. It is a qualitative study with a non-probabilistic sample for convenience that was composed of 30 young people between the ages of 18 and 23, who are in the first job as a Young Apprentice as an administrative assistant of a CompanySchool Integration Center located in Paraíba, Brazil. For data collection, two instruments were used: a questionnaire containing socio-demographic data and a questionnaire guided by the objects of the study in question, analyzed by thematic and categorical content 
analysis technique. It was possible to realize that for the majority of the young people their initial motivation to work is in the remuneration, experience and help the family and their motivation to continue working consisted in achieving independence and professional success. These results relate to the motivational theory of Maslow's
Hierarchy of Needs and have implications for the attention of the authorities on the healthy insertion of the young person in the labor market, considering that the first professional steps have effects in the career of this generation and in the future of the companies and the country.

Keywords: Motivation; young apprentice; job

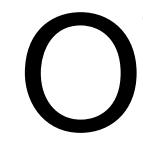

Trabalho provoca mudanças na vida do indivíduo, sejam elas positivas ou negativas, pois as relações dinâmicas que envolvem esse ambiente afetam diretamente a subjetividade do trabalhador (Dejours \& Gernet, 2012). A experiência laboral implica em invenção e criatividade, pois é a expressão da inteligência prática. Para a análise da psicodinâmica, através do trabalho o indivíduo cria a expectativa de dar uma contribuição em troca de uma retribuição simbólica, que é expressa através do reconhecimento, o qual se direciona ao serviço oferecido, mas que contribui fortemente com a realização pessoal e identidade do trabalhador (Dejours, 2004).

Os questionamentos que são feitos às crianças sobre "o que querem ser quando crescer?" demonstram a centralidade do trabalho na vida das pessoas e que é perpassado sócio historicamente. Dejours (2004) questiona se basta estar em qualquer trabalho ou se perguntar "qual trabalho?". Diante da pressão capitalista, concorrência e falta de oportunidade, muitos jovens se submetem a funções que não correspondem ao seu desejo de profissão, e isso se relaciona com a motivação para o trabalho, se é uma questão financeira ou de satisfação pessoal.

Como fruto dos processos de urbanização, industrialização e modificações sociais e econômicas, os países da América Latina carregam a precarização na inserção do jovem no mercado de trabalho ao lado da ausência em investimentos na qualificação e na estabilidade profissional deste público (Aguilera, 2016, Dornelles, Panozzo, \& 
Reis,2016). O estudo de Dornelleset al. (2016) mostrou que as ações realizadas para a inserção do jovem no mercado não conseguem atender as reais necessidades daqueles que estão em vulnerabilidade social. Para piorar seu quadro, eles se culpam pela não inserção no trabalho, ou mesmo, por não conseguirem se manterem no mercado.

Conseguir um emprego tem se configurado como um desafio para essa geração jovem, pois, ao ser contratado, enfrenta uma série de dificuldades pertencentes ao ambiente laboral e que somarão com as transformações da sua própria fase de desenvolvimento (Oliveira \& Godoy, 2015). A situação se agrava em contextos de baixo nível socioeconômico, pois os familiares incentivam a busca pelo trabalho para auxiliar nas despesas da casa, mas não conseguemorientá-los sobre os contornos que envolvem o ambiente laboral (Amazarray, Thomé, Lazzaretti de Souza, Poletto, \& Koller, 2009).

O sistema de gestão tem provocado violentos métodos para organizar o trabalho, de modo que as consequências psicológicas das relações sociais no trabalho têm ficado em segundo plano à medida que a gestão utiliza técnicas para conseguir impor a lógica da rentabilidade aos funcionários. Conforme Dejours, (2004) "trabalhar não é somente produzir; é, também, transformar a si mesmo e, no melhor dos casos, é uma ocasião oferecida à subjetividade para se testar, até mesmo para se realizar" (p. 30). Por isso, o adolescente se transforma conforme a experiência de trabalho e a motivação exerce um papel importante nessa transformação.

Para tanto, por um lado, ressalta-se a colaboração dos estudos de Dejours (2004) para a centralidade que o trabalho ocupa na vida das pessoas e por outro lado, destaca-se a perspectiva da teoria maslowniana que aponta para uma pirâmide com uma estrutura das necessidades que atravessa o próprio desenvolvimento humano. De tal forma, que, no primeiro momento, os bebês correspondem as necessidades fisiológicas e à medida que acontece o amadurecimento surgem as necessidades de 
segurança, necessidades de filiação e de estima até a busca da autorrealização com o início da adolescência (Bridgman, Cummings, \& Ballard, 2019).

Segundo Maslow (1954), uma necessidade básica frustrada pode tomar o caminho das psicopatologias.Considera-se a influência do trabalho na formação da identidade ocupacional dos jovens, em que na experiência do ser social em contato com o trabalho, estepassa a assumir papéis, valores e novos conhecimentos. O presente estudo buscou, a partir de uma perspectiva qualitativa com jovens que se encontram trabalhando no primeiro emprego,investigar qual foi a sua motivação para começar a trabalhar e compreender também quais passaram a ser a sua motivação em continuar trabalhando.

\section{Jovem e Trabalho}

Entre o século XII ao XVII a criança já se tornava útil na economia familiar, pois a partir dos 7 anos já eram vistas como miniaturas de adultos, realizando tarefas, imitando seus pais e suas mães, acompanhando-os em seus ofícios e cumprindo, assim, seu papel perante a coletividade. A partir do século XVII a fragilidade da infância demandava uma nova ação social que se importasse com o seu saudável desenvolvimento longe de negligência e abusos (Silva, 2015).

Nesse sentido, no Brasil, o Estatuto da Criança e Adolescente - ECA surge para proteger de forma integral à criança e ao adolescente, assim, proíbe o trabalho para os menores de 14 anos. Em 2000 a "Lei de Aprendizagem" (Lei no 10.097, de 2000) passa a regularizar o trabalho de um adolescente adequando-o ao seu estágio maturacional na busca de proteger os aspectos biopsicossociais na inserção do jovem no mercado de trabalho.

Mesmo com o incentivo de programas para a inserção dos jovens no mercado, SilvaFilho, Ferreira-da-Silvae Queiroz (2015) esclarecem que o mercado de trabalho para a juventude se caracteriza de maneira hostil, com informalidade, baixos salários e altos 
índices de rotatividade. Mas, é importante notar que a experiência do trabalho não acontece de forma homogênea para todos os adolescentes, pois existem particularidades e níveis de complexidade que os diferem (Oliveira, Piccinini, \& Bitencourt, 2012) em especial a partir da motivação para querer trabalhar.

A inserção no trabalho significa uma transição da infância para uma vida adulta responsável e que ao revelar uma contribuição produtiva para a sociedade, pode gerar mudanças intensas nos comportamentos, papéis sociais e nas relações interpessoais dos jovens (Dornelleset al., 2016). Nesse cenário, a motivação no trabalho possui um importante papel, como uma força misteriosa capaz de impulsionar o jovem noenfrentamento de dificuldades e alcance dos objetivos no ambiente organizacional.

\section{Motivação no Trabalho}

Entre os desafios da gestão, a motivação humana é um dos mais complexos pelo seu caráter subjetivo. Nesse sentido, muitas pesquisas estão sendo realizadas para tentar suprir essa lacuna, mas não há consenso nas discussões sobre a motivação e trabalho de forma que existem atualmente inúmeras teorias motivacionais (Latham, 2012). Está posto que esse constructo influencia o comportamento das pessoas em direção a algo desejado, mas ainda há muitas contradições sobre o que seria afinal a motivação.

Segundo Dejours e Abdoucheli (1994) é complicado definir a motivação ou debruçar sobre o conteúdo desse conceito, ainda mais que uma reflexão exaustiva seria embaraçosa. Por isso, para Dejours e Abdoucheli (1994), a motivação como causa ou como fonte dos comportamentos continua sem explicação.

Considerando a complexidade do assunto e a vasta literatura que percorre a motivação, se atentou para uma das mais representativas no campo da Psicologia: A Teoria da Hierarquia das Necessidades de Maslow, proposta na primeira metade do século XX e que ainda hoje fundamenta diversos trabalhos acadêmicos e intervenções 
organizacionais (Bridgmanet al., 2019; Farias, 2020; Silva, Uller, Santo, \& Rezende, 2017).

A importância dessa teoria para a realização pessoal vai além do alcance de objetivos, pois reflete sobre os propósitos de vida de cada um e do que precisam para ser feliz, indo afundo no que está por traz da motivação. Este modelo oferece uma compreensão do que se passa com as pessoas no ambiente de trabalho, e permite analisar a situação dos jovens que buscam mante-se em seu primeiro emprego, desde a base da pirâmide proposta pelo referido autor até seus níveis mais altos.

Para Maslow (2013) a necessidade quer dizer a privação de alguma satisfação e é isso que daria origem a energia das motivações para alcançar essa satisfação. Por isso, se alguém sente sede, bebe; se está com sono, dorme; uma vez que a necessidade seja suprida, esta não exerce mais influência no comportamento. Seguindo um nível hierárquico de uma pirâmide em que as necessidades diferem qualitativamente, quando uma necessidade é resolvida, a próxima necessidade da pirâmide será a dominante.

Na base da pirâmide se encontram as necessidades de nível baixo, que são as necessidades fisiológicas (fome, sede, abrigo sexo e outras necessidades corporais) e de segurança (proteção contra danos físicos e emocionais); por sua vez, na ponta da pirâmide se encontramas necessidades de nível alto, como necessidades sociais (afeição, aceitação, amizade e sensação de pertencimento a um grupo), de estima,com fatores internos (respeito próprio, realização e autonomia), fatores externos (status, reconhecimento e atenção) e necessidade de auto realização que representa a intenção de tornar-se tudo aquilo que a pessoa é capaz de ser; incluindo o crescimento, autodesenvolvimento e alcance do próprio potencial (Maslow, 2013). No presente artigo, coteja-se a teoria das necessidades humanas de Maslow com conceitos da Psicodinâmica do Trabalho. Apesar da primeira possuir uma base comportamental e a segunda ter uma inspiração na psicanálise, entende-se que 
ambas oferecem elementos que podem ser utilizados para a compreensão da situação que vivem os participantes desta pesquisa. Os textos de Dejours não tratam diretamente do tema da motivação, a não ser em um deles (Dejours \& Abdoucheli, 1994) no qual, a partir da Psicanálise, ele diz preferir abordar a questão a partir da noção de desejo, e não a da motivação. Por este motivo, mesmo valendo-nos da psicodinâmica do trabalho, avaliamos que seria necessário analisar a situação dos participantes com uma teoria motivacional sólida, como a de Maslow mostrou ser com o tempo (Latham, 2012).

\section{Método}

Este estudo corresponde a uma pesquisa de campo, de natureza qualitativa e caráter descritivo e exploratório. Segundo Minayo (2017) a pesquisa qualitativa visa apreender a visão de um grupo social ou de uma organização sobre um constructo pesquisado, se aprofundando nas opiniões dos participantes, o que não se restringe à operacionalização de variáveis.

\section{Participantes}

Contou-se com uma amostra não probabilística, por conveniência, formada por 30 jovens aprendizes de um Centro de Integração Empresa - Escola que fica localizado na região metropolitana de João Pessoa - PB, Brasil. A escolha do número de participantes foi respaldada nos pressupostos de representatividade de abrangência/profundidade e de saturação das categorias estudadas (Minayo, 2017).

Os critérios de inclusão da amostra que foram atendidos são: estar na faixa etária entre 18 e 24 anos, que estejam trabalhando na primeira oportunidade de emprego há no mínimo 4 meses e no máximo 1 ano (para que já tenham tido uma experiência de adaptação ao trabalho e se consiga apurar efeitos recentes); que já tenham participado de algum processo seletivo de emprego em que não foram aprovados(para 
buscar a natureza insistente da motivação) e que estivessem cadastrados no banco de dados do programa Jovem Aprendiz (por ser um trabalho regularizado pela Lei para a juventude).

Como resultado do questionário sociodemográfico, a Tabela 1 mostra o perfil dos jovens entrevistados que foi composto por maioria do sexo femininocom idades entre 20 e 23 anos, com a renda familiar entre 1 e 2 salários mínimos, o que representa jovens em uma classe econômica baixa. No tocante a escolaridade, a maioria se encontra com o Ensino Médio completo, sem nenhum vínculo com alguma formação e com total disponibilidade para trabalhar, pode-se questionar qual a perspectiva profissional desta maioria que não ingressouno ensino superior, mas já se encontra atuando no mercado.

A Tabela 2 se refere a função ocupacional e mostra que todos os jovens entrevistados se encontravam atuando na experiência do primeiro emprego como jovem aprendiz na função de assistente administrativo em diferentes organizações do ramo comercial (alimentação, calçado e vestuário) com um período de tempo de serviço que variou de quatro a seis meses.

Tabela 1

Caracterização dos participantes

\begin{tabular}{lcc} 
& VARÍÁVEIS & $\begin{array}{c}\text { DISTRIBUIÇÃO DOS } \\
\text { PARTICIPANTES }\end{array}$ \\
\hline $\begin{array}{c}\text { Feminino } \\
\text { Masculino }\end{array}$ & SEXO & 19 \\
& FAIXA ETÁRIA & 11 \\
Entre 18 e 19 & 10 \\
Entre 20 e 23 & 20 \\
Solteiro & ESTADO CIVIL & 28 \\
Casado & & 2 \\
\hline
\end{tabular}


Tabela 1 Caracterização dos participantes (continuação)

\begin{tabular}{lc}
\hline \multicolumn{1}{c}{ VARÍÁVEIS } & $\begin{array}{c}\text { DISTRIBUIÇÃO DOS } \\
\text { PARTICIPANTES }\end{array}$ \\
\hline RENDA & 26 \\
Entre 1 a 2 Salários Mínimos & 4 \\
Entre 3 a 4 Salários Mínimos & \\
ESCOLARIDADE & 2 \\
Ensino Médio Incompleto & 19 \\
Ensino Médio Completo & 9 \\
Ensino Superior Cursando & 9 \\
\hline
\end{tabular}

Tabela 2

Função ocupacional dos participantes

FUNÇÃO OCUPACIONAL / CURSO DE DISTRIBUIÇÃO DOS

APRENDIZAGEM

PARTICIPANTES

\begin{tabular}{lc}
\hline Assistente Administrativo & 30 \\
TIPO DE ORGANIZAÇÃO DO RAMO & \\
Alimentação & 8 \\
Calçado & 10 \\
Vestuário & 12 \\
\hline
\end{tabular}

\section{Instrumentos}

Foram utilizados dois instrumentos: um questionário sociodemográfico para caracterizar o perfil dos participantes (sexo, idade, estado civil, nível de escolaridade, renda mensal e emprego) e um questionário com 2 perguntas norteadas pelos objetivos do estudo, a saber: Investigar por meio de jovens que se encontram vivenciando a experiencia do primeiro emprego qual foi a motivação para começar a trabalhar e qual foi a motivação para continuar trabalhando. Foram disponibilizadas uma caneta e uma folha de papel com um espaço de até30 linhas para cada resposta. 


\section{Procedimento}

Para a coleta dos dados, primeiramente foi agendada uma reunião com a coordenação da empresa-escola para o estabelecimento dos dias e horários mais adequados para a aplicação dos questionários, que aconteceu individualmente em um local reservado, livre de barulhos ou interrupções. Depois de dois meses, a pesquisadora marcou um novo encontro individual com os participantes no mesmo local da coleta da pesquisa para validação das respostas, ocasião em que os jovens opinaram se concordavamou não com as interpretações dadas as suas respostas.

Todas as diretrizes e normas da Resolução CNS no 510/16 relativas ao tratamento ético em pesquisa com seres humanos foram seguidas e atendidas neste manuscrito. A aprovação do trabalho pelo Comitê de Ética da Instituição está vinculada ao número de registro 71102017.4 .00005176 .

\section{Análise de Dados}

Para a realização da análise de dados, optou-se pelo método da análise do conteúdo categorial temática. Segundo Minayo (2017), a análise de conteúdo utiliza procedimentos sistemáticos de descrição que possibilite a análise dos saberes sobre às condições perguntadas. Desse modo,tentou-se verificar a existência decategorias conceituais que possibilite a interpretação do sentido do conteúdo, através de opiniões com significados semelhantes que sejam capazes de compor uma categoria representativa do grupo. Cada categoria expressa uma classe de subcategorias compostas por palavras chaves que dão sentido a esta e que resumem as unidades temáticas, ou seja, as respostas propriamente escritas. 


\section{Resultados e Discussão}

O resultado da análise de conteúdo gerou um conhecimento baseado em 13 subcategorias distribuídas em 5 categorias que serão expostas em 2 eixos temáticos como mostram as tabelas a seguir:

Tabela 3

Motivação para começar a trabalhar

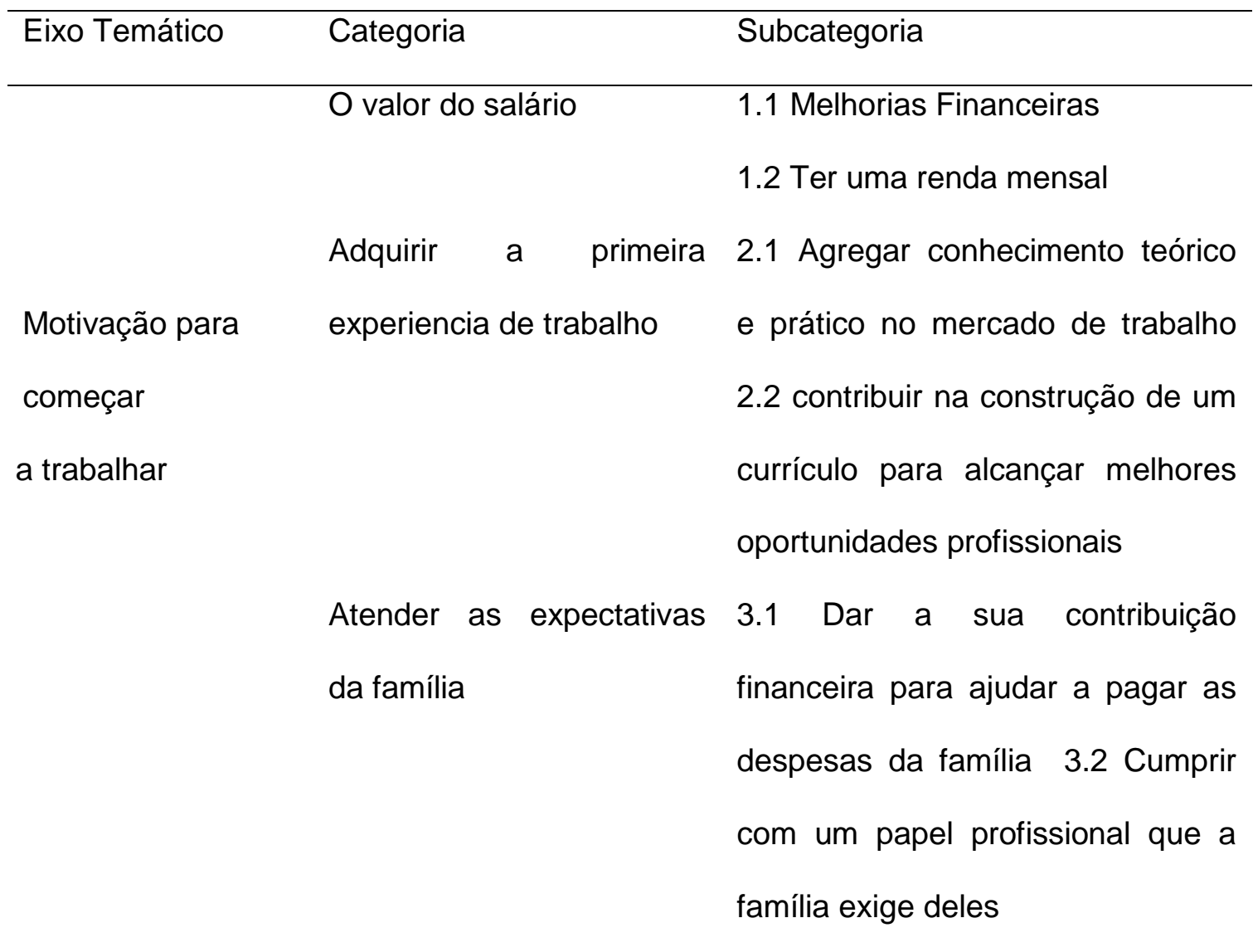

No tocante à motivação dos jovens para começar a trabalhar, a Tabela 3 mostra que, assim como foi identificado nos dados sociodemográfico uma maioria com o nível socioeconômico baixo, percebe-se que na busca do primeiro emprego dos jovens que estão em vulnerabilidade social há pouca liberdade de escolha, existe a necessidade de sobrevivência e em tempos de restrição de vagas, qualquer emprego parece ser 
útil, mesmo que não seja o que eles gostariam de fazer. Como mostra a fala do participante 6: "o que me motivava era o dinheiro que ia receber todo mês, pensava muito nisso, pois estava precisando, então não importava qual emprego, só queria está recebendo meu dinheiro".Nessa linha, Oliveiraet al. (2012) relatam que a atual situação política e econômica do trabalho demonstra a fragilidade e escassez do desemprego juvenil estrutural. Como mostra uma escrita do participante 1:

Se não fosse por causa do salário, eu não estaria procurando emprego naquela época, pois fui muito humilhado, recebi muitos "nãos", em cada lugar que ia para tentar encontrar um emprego era uma nova decepção, mas eu precisava do dinheiro, por isso não desisti.

O trabalho apresenta uma oportunidade de ascensão social para os jovensde classe socioeconômica baixa, como uma fonte motivacional para modificar a sua situação e alcançar melhores oportunidades profissionais no futuro. Mas os altos índices de desempregorevelam uma omissão de responsabilidade para as consequências do trabalho na saúde, no desenvolvimento da identidade e nos estudos dos jovens. De modo que essa situação implica por medidas legais e políticas públicas que atentem para proteger o trabalhador adolescente (Amazarrayet al., 2009).

Em relação à categoria adquirir a primeira experiencia de emprego, diante do contexto da precarização do trabalho que passa a afetar a maior parte dos trabalhadores, os jovens apresentam muitas inseguranças quando se depararam com um processo seletivo na tentativa de entrada no mercado de trabalho. Como revelou o que escreveu o respondente 4 :

A vontade de ter experiência era o que me motivava, pois eu nunca tinha trabalhado e toda entrevista de processo seletivo que participei me perguntavam sobre em qual empregoeu já tinha trabalhado, mas eu não tinha resposta, pois nunca tinha tido a oportunidade de ser empregada por uma empresa, por isso, sentia o olhar de decepção do entrevistador, parece que 
queriam sempre alguém com experiência, então eu imaginava que quanto mais experiência eu tivesse, maior a chance de ter sucesso profissional no trabalho. Garbin e Silva (2016) abordam que o perfil profissional que as empresas procuram é guiado pela ideia da flexibilidade toyotizada que muitas vezes se anula quanto asubjetividade do sujeito que precisa corresponder às demandas capitalistas da empresa em um cenário marcado por muitas injustiças e competitividade, em que as pessoas vivem com a presença constante do medo da exclusão do mercado (Fierro, 2016). Nesse sentido as exigências organizacionais muitas vezes não se acompanham de paciência e tempo para propiciar um melhor desenvolvimento profissional para os jovens que estão começando a sua carreira. O participante 8 escreveu: "me motivava ter a oportunidade de trabalhar, mostrar que tenho facilidade de aprender coisas novas e que sou capaz".Percebe-se que os obstáculos que os jovens estão enfrentando para conseguirem um emprego podem ser justificados pelo pouco contato profissional que poderá ser visto como motivo de custo para as instituições.

Além disso, há desafios de interesses conflitantes na constituição de programas que apesar de buscarem a inserção dos jovens no mercado de trabalho, possuem uma atuação limitada e incluir ações que correspondam as demandas de qualificação profissional não é algo simples (Nunes \& Fernandes, 2016). O estudo realizado por Aguilera (2016)mostrou que as políticas de emprego que são desenvolvidas para os jovens na América Latina partem de uma perspectiva de igualdade social que segue a lógica capitalista. Assim, há um investimento na adequação do jovem a um sistema de trabalho com um ritmo elevado de produtividade, o que afeta fortemente a subjetividade desse público, compromete a sua saudável inserção no mercado de trabalho e deixa sequelas na sua identidade ocupacional.

Para tanto, é necessário que a heterogeneidade das realidades desse público juvenil seja considerada no surgimento de políticas que envolvam o comprometimento 
coletivo do Estado e da sociedade e na reformulação dos programas de capacitação que alcancem uma maior compreensão das especificidades sociais como influentes no cotidiano de trabalho dos jovens.

Em relação à categoria identificada como atender as expectativas da família, percebese uma coerência com a literatura existente sobre a importância da família na inserção do jovem no trabalho (Amazarrayet al., 2009). O participante 19 aborda que "a minha mãe sempre me motivava a trabalhar, inclusive ela procurava as oportunidades de trabalho junto comigo, me levava na entrevista e estava sempre ali". Por isso, a situação financeira da família do jovem é um importante fator de motivação no trabalho, em consonância, o respondente 6 escreveu:

Minha família é tudo para mim, me doía ver eles passando necessidade, só queria ajudar e minha mãe também vivia dizendo pra mim e meus irmãos "vocês tem que arranjar um trabalho, dinheiro não cai do céu", por isso fui correr atrás de emprego, precisava colaborar.

Percebe-se a naturalização do trabalho em famílias com nível socioeconômico baixo, pois enaltecem as características positivas do trabalho e minimizam as consequências deletérias, porentenderem que sua obrigação é auxiliar no estudo dos filhos até o término do Ensino Fundamental, momento em que estes devem começar a trabalhar para ajudar nas despesas domésticas. 
Tabela 4

Motivação para continuar trabalhando

\begin{tabular}{ccl}
\hline $\begin{array}{c}\text { Eixo } \\
\text { Temático }\end{array}$ & \multicolumn{1}{c}{ Categoria } & \multicolumn{1}{c}{ Subcategoria } \\
& & \\
\hline \multirow{3}{*}{ 1. Satisfação Laboral } & 1.1 Conquistar os objetivos \\
Motivação & 1.2 Esperar um futuro melhor \\
para & 1.3 Receber olhares de orgulho \\
continuar & 2. Independência & 1.4 Sucesso e crescimento \\
trabalhando & 2.1Ter meu próprio dinheiro \\
& & 2.2 Arcar com meus gastos \\
& & 2.3 Suprir as necessidades. \\
\hline
\end{tabular}

Em relação à motivação dos jovens para continuar trabalhando a Tabela 4 mostra que emergiram as categorias satisfação laboral eindependência, a maioria dos jovens aprendizes revelaram a importância do sucesso profissional e independência, como mostram as respostas dos seguintes jovens:

R5 - Conquistar os objetivos e ter a esperança de um futuro melhor. R19 Receber olhares de orgulho e suprir minhas necessidades. R1- Obter sucesso e crescer profissionalmente comdedicação e esforço. R21 -Agregar conhecimento no mercado de trabalho e assim, contribuir na minha vida profissionalmente. R8 - Ter meu próprio dinheiro e arcar com os meus gastos.

As respostas mencionadas corroboram com 0 resultado de uma pesquisa desenvolvida por Garbin e Silva (2016) em que jovens de contextos diversos relataram como principais motivos para trabalhar: a auto realização, a independência, o crescimento e a necessidade. Além disso, existe o medo da permanência na casa dos pais, recebendo ajuda financeira e não conseguindo caminhar sozinhos em busca da independência. A motivação para manter-se no emprego, portanto, traz consigo os aspectos relativos ao nível mais baixo da pirâmide de Maslow, a saber, das necessidades fisiológicas, no que diz respeito à capacidade de comprar suprimentos 
para a manutenção da sua vida, mas não se restringe a ele, na medida em que aponta também para a necessidade de segurança, especialmente no emprego, de se sentir amado pelos outros, reconhecido por eles e, assim, poder aumentar sua autoestima e sentindo-se realizado.

Ressalta-se que com a reestruturação produtiva as empresas estão formando um perfil de trabalhador flexível e competitivo. O mundo contemporâneo glorifica o sucesso individual e a superação de cada um para enfrentar os desafios por seus próprios métodos (Dejours, 2004). Nesse sentido, o ambiente de trabalho enfatiza o individualismo à medida que a força dos coletivos se fragiliza e a subjetividade não se é levada em conta, o que traz implicações para o desenvolvimento dos jovens e a sua motivação para trabalhar (Menetti, Kubo,\& Oliva, 2015). Nesse aspecto, o respondente 7 mencionou:

Minha motivação para continuar no trabalho é ser uma pessoa bem sucedida, reconhecida e valorizada no meu emprego, quero que minha família se orgulhe de quem eu me tornei e tenho medo de ser demitido ou de não conseguir chegar no sucesso.

Neste ponto, a falta de segurança no emprego (segundo degrau na hierarquia de Maslow) é uma ameaça que atinge a todos, mas que é vivido por cada trabalhador, como sendo culpa do próprio indivíduo (Jackson Filho, Garcia, David, Duracenko, \& Simonelli, 2019). Para s jovens que começam sua carreira profissional e não logram êxito em manter-se nela, isso pode apresentar consequências pessoais e sociais terríveis, na medida em que podem passar a viver sem a noção de valor do trabalho (Dejours, 2004). Por isso, a manutenção do jovem em um emprego que seja adequado a ele deve supor esforços não apenas dele e do empregador, mas deve contar igualmente com políticas de Estado que o amparem (Pessoa, Alberto, Viana, \& Picornell-Lucas, 2019) 
Ao se depararem com o desligamento da empresa, os jovens manifestam a culpa e sofrimento quandonão atingirem o sucesso no trabalho e não conseguem se encaixar nas exigências do mercado,que éguiada pela exploração capitalista, deixando-os a mercê de condições precárias, pois a sua inserção precoce no mercado os coloca em uma posição vulnerável para os efeitos deletérios desse ambiente (Garbin \& Silva 2016).

Em comparação com a Teoria de Maslow sobre A Hierarquia das Necessidades Humanas, percebemos que osalário se relaciona com fatores externos e representa uma necessidade básica da pirâmide como motivação para começar a trabalhar. Uma vez satisfeita essa necessidade, ou seja, depois de empregados, surge na experiência do trabalho as necessidades de nível mais elevados que são satisfeitas a partir de fatores intrínsecose diz respeitoàs necessidades de auto realização ou a busca de individualização, como expressa o participante 15: "Eu vejo no meu trabalho uma oportunidade que pode abrir muitas portas para o meu crescimento e sucesso, o que me motiva é ser reconhecido como um bom profissional e ser referência no que faço". Na experiência de trabalho o jovem passa a tentar alcançar a sua essência na mais alta inspiração do ser humano, para aproveitar toda a sua potencialidade. Como o trabalho é atividade útil, estar em um emprego oferece àquele que o realiza 0 sentimento de pertencimento e de ser útil para a sociedade (Dejours \& Gernet, 2012).

\section{Considerações finais}

Diante dos objetivos apresentados, os principais resultados encontrados no tocante à motivação dos jovens para começar a trabalhar foram referentesas categorias de remuneração, como mostra a literatura, as condições financeiras exercem forte influência para o ingresso dos jovens no mercado de trabalho. Recorrendo a teoria de Maslow, o salário pode ser apresentado com uma forma para suprir as necessidades 
básicas, mas não se limita a isso, visto carregar consigo igualmente um aspecto de reconhecimento social, que passa por todos níveis superiores da pirâmide.

O surgimento da categoria experiência pode ser apoiado nas inseguranças que surgem para o primeiro emprego. Por isso, a importância da preparação de supervisores para Ihe dar com esse público de forma didática. Em consonância com os estudos já realizados, a família foi apresentada como fonte motivadora para o primeiro emprego, sendo necessário o investimento em orientação para as famílias sobre os contornos do trabalho, pois o essencial é que exista uma saudável inserção do jovem no mercado, cientes da importância da atuação profissional não apenas como fonte de renda, mas como uma realização pessoal, para que não se limitem a uma vida baseada na crença do nascer, crescer, trabalhar, pagar conta e morrer.

Foi possível inferir nas respostas da maioria dos aprendizes a importância da independência e realização pessoal como categoria para continuar trabalhando, como citado sobre a teoria de Maslow que supõe que supridas as necessidades básicas o ser humano buscará motivações impulsionadas para a sua realização pessoal. Principalmente no contexto da virada neoliberal que prioriza o lucro e a competitividade colocando novos desafios para os recursos humanos propiciar um ambiente motivador.

Para Maslow, a motivação se refere a algo intrínseco que surge nos altos níveis da hierarquia, como a autorealização. Assim, a remuneração ou condições de trabalho para ele não poderiam ser colocada como motivação, mas uma estratégia do colaborador para não se sentir insatisfeito. Nesse ponto, a teoria se desconecta do real, pois o ambiente do trabalho e as relações dinâmicas que compõem o seu envoltório são influenciadoresda motivação. O que abre espaço para novas questões que merecem ser contempladas em estudos futuros sobre os limites dos fatores internos e externos da motivação e a influência das condições de trabalho nesse processo. 
Como limitações da pesquisa, o estudo foi desenvolvido com apenas 30 jovens, e por se tratar de uma análise qualitativa, os achados não podem ser generalizados, mas ainda assim, alcançam profundidade na compreensão dos objetivos propostos. Outra limitação é que o estudo se fundamentou apenas nas respostas dos jovens e não houve contato direto com a organização de trabalho, o que sugere que novos estudos sejam desenvolvidos nesse eixo temático e que considere a ampliação das fontes de informações, por exemplo, levando em conta a fala do supervisor desse jovem no trabalho.

Esse estudo buscou gerar reflexões que alimentem a operacionalização de investimentos para com o trabalho dos jovens e a sua esperança no desenvolvimento profissional.Com os dados sobre o desemprego juvenil parte-se do princípio de que muito mais do que inserir os jovens no mercado, como o programa jovem aprendiz tem feito, é importante oferecer condições de manutenção desse trabalho para o desenvolvimento do jovem e da empresa,afim de atingir políticas públicas com a implementação de programas e serviços que auxiliem no desenvolvimento profissional daqueles que se encontram desamparados e desmotivados com a situação do trabalho.

\section{Referências}

Aguilera, G, R. (2016). Gobernar la juventud vulnerable: un analisis discursivo de las políticas de empleo juvenil en chile. Revista Pueblos y Fronteras Digital, 11(21),192-213. Recuperado de https://www.redalyc.org/articulo.oa?id=906/90645701009

Amazarray, M. R., Thomé, L. D., Lazzaretti de Souza, A. P. L., Poletto, M., \& Koller, S. H. (2009). Aprendiz versus trabalhador: adolescentes em processo de aprendizagem. Psicologia: Teoria e Pesquisa, 25(3), 329-338. doi: 10.1590/ S0102-37722009000300006 
Bridgman, T., Cummings S., \& Ballard, J. (2019). Who Built Maslow's Pyramid? A History of the Creation of Management Studies' Most Famous Symboland Its Implications for Management Education. Academy of Management Learning \& Education 18(1).doi: 10.5465/amle.2017.0351

Dejours, C. (2004). Subjetividade, trabalho e ação. Revista Production, 14(3),2744.doi: 10.1590/S0103-65132004000300004

Dejours, C.,\&Gernet,I. (2012). Psychopathologie du travail. Issy-les-Moulineaux.Paris: Elsevier Mason.

Dejours,C.,\&Abdoucheli, E. (1994). Desejo ou Motivação? A interrogação psicanalítica sobre o trabalho. In M. Betiol. (Coord.). Psicodinâmica do trabalho: Contribuições da Escola Dejouriana à análise da relação prazer, sofrimento e trabalho (pp. 34-43). São Paulo: Atlas.

Dornelles, A. E., Panozzo, V. M., \& Reis, C. N dos. (2016). Juventude latino-americana e mercado de trabalho: programas de capacitação e inserção. Revista Katálysis, 19(1), 81-90. doi: 10.1590/1414-49802016.00100009

Farias, R. F. M. (2020). Análise da satisfação dos funcionários de empresas do setor têxtil e do vestuário no distrito de Braga.Bragança:Instituto Politécnico de Bragança.

Recuperado de https://bibliotecadigital.ipb.pt/bitstream/10198/20550/1/pautarelatorio-19.pdf

Fierro, S. M. (2016). El reconocimiento y el sufrimiento de los cuerpos en el trabajo. Psicología, Conocimiento y Sociedad, 6(2), 29-47. Recuperadode http://www.scielo.edu.uy/scielo.php?script=sci_arttext\&pid=S1688$70262016000200003 \& \operatorname{lng}=e s \&$ tIng $=e s$

Garbin, A. de. C., \& Silva, H, A da. (2016). Quero trabalhar! A experiência marcante dos processos seletivos na subjetividade de jovens universitários. Cadernos de Psicologia Social do Trabalho, 9(1), 77-88.doi:10.11606/issn.1981-0490.v19i1 
Jackson Filho, J. M., Garcia, E. G., David, H. G., Duracenko, S.R. C., \& Simonelli, A. P. (2019). Acidentes de trabalho e atuação do Centro de Referência em Saúde do Trabalhador nas páginas do Jornal de Piracicaba entre 2007 e 2014. Interface Comunicação, Saúde, Educação, 23, e18065. doi: 10.1590/interface.180659

Lei n॰10.097. (2000, dezembro20). Altera dispositivos da Consolidação das Leis do Trabalho - CLT. Aprovada pelo DecretoLei no 5.452, de 1ํ de maio de 1943. Recuperado de https://fnpeti.org.br/media/legislacao/Lei_da_Aprendizagem_Lei_n\%C2\%BA_1 0.097_de_19_de_dezembro_de_2000.pdf

Latham, G. P. (2012). Work motivation: history, theory, research and practice. Thousand Oaks (CA): Sage.

Maslow, A. H. ( 1954 ). Motivationand personality. New York, NY: Harper.

Maslow, A. H.(2013).ATheory of Human Motivation. Estados Unidos da América: Lightning Source.

Menetti, S., Kubo, E.,\& Oliva, E. (2015). A geração $Y$ brasileira e o seu comprometimento organizacional em empresas de conhecimento intensivo. Revista de Gestão dos Países de Língua Portuguesa,14(2), 02-13. Recuperadodehttp://www.scielo.mec.pt/scielo.php?script=sci_arttext\&pid=S164 $5-44642015000200002 \& \operatorname{lng}=p t \& t \operatorname{lng}=p t$

Minayo, M, C, de S. (2017). Amostragem e saturação em pesquisa qualitativa: Consensos e controvérsias. Revista Pesquisa Qualitativa, 5(7), 01-12. Recuperado de https://editora.sepq.org.br/index.php/rpq/article/view/82/59

Nunes, M. B. de A., \& Fernandez, C. B.(2016). Estado, sociedade e políticas de trabalho e emprego voltadas para os jovens no Brasil. Revista Katálysis, 19(1), 64-72. Recuperado de https://www.redalyc.org/articulo.oa?id=1796/179646075007 
Oliveira, A. L., \&Godoy, M. M. da.C. (2015). O processo de resiliência do jovem aprendiz e as estratégias de conciliação estudo-trabalho. Revista Boletim de Psicologia, 65(143), 175-191. Recuperado de http://pepsic.bvsalud.org/scielo.php?script=sci_arttext\&pid=S0006$59432015000200006 \& \operatorname{lng}=$ pt\&tlng=pt.

Oliveira, A. R., Piccinini, V. C., \& Bitencourt, B. M. (2012). Juventudes, gerações e trabalho: é possível falar em geração y no Brasil? Revista Organização e Sociedade,19(62), 551-558. Recuperado de http://www.scielo.br/scielo.php?script=sci_arttext\&pid=S198492302012000300010

Pessoa, M. C. B., Alberto, M.de F. P.,Viana,O. J.,\& Picornell-Lucas, A. (2019). Juventude e formação: a política pública de formação profissional como cenário. Revista Estudos Interdisciplinares em Psicologia 10(1) 153-172. Recuperado de: https://www.researchgate.net/publication/333670663_Juventude_e_formacao_ a_politica_publica_de_formacao_profissional_como_cenario

Silva,I. Y. M. (2015). Um estudo historiográfico sobre a psicanálise com crianças no contexto universitário. (Trabalho de graduação - Faculdade de Ciências e Letras de Assis). Recuperado de http://hdl.handle.net/11449/139424

Silva-Filho, L. A., Ferreira da Silva, F, J.,\& Queiroz, S. N.(2015). Jovens no mercado de trabalho formal brasileiro: uma análise quantitativa. Revista Faculdade de Ciências, (2), 21-34. doi: 10.18359/rfce.1605

Silva, V. L., Uller, C. M., Santos, J. D.,\&Rezende, F. A. (2017). Análise da motivação de pessoas: um estudo baseado em princípios da hierarquia de necessidades de Maslow. Revista Foco 10(2). doi: 10.28950/1981223x_revistafocoadm/2017.v10i2.365 


\section{Agradecimentos}

À CAPES pela bolsa de pesquisa concedida a primeira autora do manuscrito e ao CNPq pela bolsa de pesquisa concedida ao segundo autor do manuscrito.

\section{Declaração do contributo dos autores}

AD contribuiu no desenho, implementação da investigação e na análise dos resultados e PC contribuiu na escrita do manuscrito e na formulação do aporte teórico utilizado. Todos os autores discutiram os resultados e contribuíram para a versão final do manuscrito.

\section{Editor se sección}

La editora de sección de este artículo fue Karina Curione.

ORCID ID: 0000-0002-4069-5615

\section{Formato de citación}

Dourado, A. D.,\& Zambroni-de-Souza, P.C. (2020). Motivação e trabalho: investigação sobre a experiência dos jovens no primeiro emprego. Psicología, Conocimiento y Sociedad, 10(2), 6-29. doi: http://dx.doi.org/10.26864/PCS.v10.n2.1 